\title{
A NEW ROACH FROM THE PHILIPPINES.
}

BY A. N. CAUDELL, WASHINGTON, D. C.

Salganea humeralis, new species.-Size medium. General colour black, the under surface of the legs and of the body, except the last abdominal segment, or subgenital plate, and the mouth, except the mandibles, and also the vertex, reddish. The base of the elytra in the anal field is also tinted with reddish. Antennæ dark, hairy. Wings and elytra mostly missing. Anterior femora unarmed. Pronotum very slightly notched anteriorly, the disk with the usual irregular V-shaped depression and unequal elevations, but not distinctly tuberculate, the entire surface punctate. Base of the elytra smooth in the anal field, the costal field densely and coarsely punctate. Abdomen punctured, finer below along the median line, the segments transversely sulcate anteriorly above, more profoundly so towards the sides of the last three; seventh segment laterally irregularly crenulate, the latero-posterior angles divergent. Supra-anal plate rugulosely punctate, the posterior margin dully serrate; subgenital plate marked as the supra-anal plate, posteriorly emarginate. Cerci short, triangular, hairy, reddish in colour.

Length, $30 \mathrm{~mm}$.; pronotum, $7.5 \mathrm{~mm}$.; width, pronotum, I I $\mathrm{mm}$.; abdomen, $14 \mathrm{~mm}$.

Type No. 9812 , U.S.N.M.

One female, one nymph, received from C.S. Banks, of Manilla, P.I, no definite locality given.

This species seems to be the most nexrly allied to Salganea rugulata of Saussure. but is decidedly larger than that species. The organs of flight are much mutilated, as is so often the case with members of this genus, as well as Panesthia, and probably other related genera. The elytra and wings are apparently chewed off, and so uniformly as to appear like a short-winged form, if not carefully examined. Of the three species of Salganea and Panesthia examined by me, more than one half of the specimens are thus mutilated. I can assign no plausible cause for the phenomenon.

The nymph is reddish yellow, lighter below, except towards the tip of the abdomen. The punctlires of the surface are not so deep nor distinct as in the adult.

$\Lambda$ pril, Igo6. 